\title{
MHD FORCED CONVECTION USING FERROFLUID OVER A BACKWARD FACING STEP CONTAINING A FINNED CYLINDER
}

\author{
Meriem TOUMI ${ }^{\star}$, Mohamed BOUZIT $^{* \oplus}$, Fayçal BOUZIT $^{*}$, Abderrahim MOKHEFI $^{* *}$ \\ *Laboratory of Maritime Sciences and Engineering LSIM Faculty of Mechanical Engineering, \\ University of Science and Technology of Oran, Mohamed Boudiaf, El Mnaouar, B.P.1505, 31000, Oran, Algeria. \\ ${ }^{* *}$ Mechanics, Modeling and Experimentation Laboratory L2ME, Faculty of Sciences and Technology, \\ Bechar University B.P.417, 08000, Bechar, Algeria, \\ meriem.toumi@univ-usto.dz, bouzit_mohamed@yahoo.fr, faycal.bouzit@yahoo.fr, abderrahim.mokhefi@univ-bechar.dz
}

received 21 September 2021, revised 15 November 2021, accepted 2 December 2021

\begin{abstract}
In this paper, a numerical study of forced convection on a backward facing step containing a single-finned fixed cylinder has been performed, using a ferrofluid and external magnetic field with different inclinations. The partial differential equations, which determine the conservation equations for mass, momentum and energy, were solved using the finite element scheme based on Galerkin's method. The analysis of heat transfer characteristics by forced convection was made by taking different values of the Reynolds number (Re between 10 and 100), Hartmann number (Ha between 0 and 100), nanoparticles concentration ( $\varphi$ between 0 and 0.1 ) and magnetic field inclination ( $y$ between $0^{\circ}$ and $90^{\circ}$ ); also, several fin positions a $\left[0^{\circ}-180^{\circ}\right]$ were taken in the counter clockwise direction by a step of 5 . After analysing the results, we concluded that Hartmann number, nanoparticles concentration, Reynolds number and magnetic field angles have an influence on the heat transfer rate. However, the fin position on the cylinder has a big impact on the Nusselt number and therefore on heat transfer quality. The best position of the fin is at $\left(\alpha=150^{\circ}\right)$, which gives the best Nusselt number and therefore the best heat transfer, but the fin position at $\left(\alpha=0^{\circ}\right)$ remains an unfavourable case that gives the lowest Nusselt values.
\end{abstract}

Key words: fin positions, forced convection, nanoparticles, heat transfer, finned cylinder, magneto-hydrodynamic, backward facing step

\section{INTRODUCTION}

The presence of the singularities on the fluid flows in the duct causes changes in the characteristics of the flow and heat transfer, and this is the reason for the sudden expansions or backward facing step being of great interest in many industrial applications. It was performed a numerical analysis to study the effect of Reynolds number on the flow characteristics; the results obtained indicated that the sizes of recirculation zones are influenced by variation of Reynolds number [1-2]. A numerical investigation was carried out a on a backward facing step to study the effect of Reynolds number and the aspect ratio on the separation and reattachment fluid flow and heat transfer characteristics. A significant influence on heat transfer was observed [3-4]. A mixed convection using different values of control parameters such as Reynolds number, Richardson number and Grashof number was numerically studied. Their results indicate that there exists an effect on structure of fluid flow and heat transfer and that a secondary recirculating flow always occurs inside the primary recirculation zone [5-6]. A numerical simulation of forced convection to study the effect of the Prandtl number on mean temperatures, heat transfer coefficients and heat fluxes was presented. Therefore, for low Prandtl numbers, the Nusselt number achieves the smaller value. The maximum heat transfer location moves upstream of the reattachment point for larger Prandtl numbers [7]. An oscillating fin had mounted on the top wall of backward facing step; the oscillating fin was identified as the most effective method since it involved the highest average Nusselt number and lowest pressure drop; also, there is negligible change in average Nusselt number resultant to the increase in the oscillation amplitude [8]. A circular cylinder was added in a duct. The Nusselt number reaches a maximum value of $155 \%$ compared to the case of a geometry without a cylinder [9].

Convective heat transfer of fluid flows in presence of nanoparticles and magnetic field are intensively studied. The use of nanofluids under the influence of the magnetic field has become one of the most prominent researched topics in recent times. It was observed that when the Reynolds number and nanoparticles volume fraction increase, the rate of heat transfer increases. Increase in Hartmann number causes a degradation in the rate of heat transfer [10]. The effect of step height on flow and characteristics of heat transfer studied by [11], they observed that average Nusselt number and skin friction coefficient increase with the increase of the step height. Numerical investigations of convective flow to study the effect of nanoparticles' insertion in base fluid on heat transfer quality was performed by [12-17]. They observed that average Nusselt number increases with increasing nanoparticles' fraction volume relative to the pure fluid (without the presence of the nanoparticles). Nanoparticles cause changes in the characteristics of flow, increase vortices number and improve mass transfer. [18-19] investigated the effect of Baffle locations at the top wall and at the bottom wall of a duct; based on the analysis of their numerical results, they indicate that the effects of distance height baffle and their locations on fluid flow and characteristics of heat transfer are significant. When length baffle increases, the recirculation region behind the backward facing step shrinks and average Nusselt number increases by increasing the length baffle. The blockage shapes had used, and their effect on nanofluids' convective flow was studied [20-22]. Their results 
indicate that average Nusselt number takes the highest value when triangular blockage shapes are added on backward facing step. For trapezoidal blockage shapes, average Nusselt number is lowest. In addition, they observed that heat transfer enhancement is obtained for angular velocities $\Omega=-4.5$ and 1.5 in the cylindrical blockage shapes' case. [23-28] set out to study thermal transfer control and quality; for this purpose, they used the presence of the external magnetic field with inclination. Magnetic dipole force and a rotate cylinder can control the length and size of the recycle zones. They observed that an inclined and vertical magnetic field causes the elimination of the recycle zone behind the step. Cylinder rotation affects distribution of Nusselt number. Heat transfer rate improves when Reynolds number is high. In other research, it was discussed that most degraded heat transfer rates achieved with partial magnetic field were centred on walking. Magnetohydrodynamic study of natural convection involves an inclined Tshaped enclosure filled with different types of nanofluids using Rayleigh number and Hartmann number and the performance of magnetic field inclination. Average Nusselt number increases with increasing Rayleigh number, magnetic field inclination, heat source location and size of nanoparticle fraction, while it decreases with increasing Hartmann number.

Using the ferrofluid $\mathrm{Fe} 3 \mathrm{O} 4-\mathrm{H} 2 \mathrm{O}$ and the presence of the external magnetic to study forced convective flow inside a backward facing step comprising a rotating cylinder of fixed diameter [29]. They show that increasing Hartmann number implies a decrease in average Nusselt number, but when increasing Reynolds number, concentration of nanoparticles and magnetic field inclination, as well as the mean number of Nusselt, increase. In addition, when the cylinder rotates counter clockwise, the heat transfer rate improves.

Studies are always carried out to find the best method and the best tool to achieve a most significant improvement in the rate of heat transfer by the use of control parameter and especially the addition of nanoparticles in the base fluid, in presence of external magnetic field.

In the present work, adding a single fin on a fixed cylinder is the main parameter used. Forced convection flow of a ferrofluid on a backward facing step containing a single fin attached to a fixed cylinder in the presence of an external magnetic field with different inclinations is studied. The present study was made by taking different values of the Reynolds number (Re between 10 and 100), Hartmann number (Ha between 0 and 100), nanoparticles concentration ( $\varphi$ between 0 and 0.1 ) and magnetic field inclination ( $\gamma$ between $0^{\circ}$ and $90^{\circ}$ ), along with considering several fin positions a $\left[0^{\circ}-180^{\circ}\right]$. Certain positions of the fin prove their effectiveness in improving the heat transfer phenomenon, while other positions have shown an unfavorable effect on the heat transfer rate. This investigation does not currently find place in the literature, to our knowledge.

\section{PHYSICAL PHENOMENON}

\subsection{Description of backward facing step configuration}

In the present work, a 2D numerical study of the forced convection of a laminar and Newtonian ferrofluid flow, on a backward facing step containing a single fin fixed on a cylinder, is performed in the presence of a magnetic field with different inclinations; the physical configuration with boundary conditions are presented in Fig. 1. The one phase ferrofluid model is used. The height of the backward facing step is $H$ and the height of the channel is $2 \mathrm{H}$. $\gamma$ is the inclination angle of the external magnetic field, $D$ is the diameter of the fixed cylinder where the position is at $(4 \mathrm{H}, \mathrm{H})$ and the length of the fin is $0.4 \mathrm{H}$. At the inlet $\left(T=T_{\mathrm{c}}\right)$ represents the cold flow and parabolic velocities are imposed. At the lower wall downstream $\left(T=T_{h}\right)$ is the hot temperature. The other walls are adiabatic and have no slip velocity (Fig. 1). The viscous dissipation, thermal radiation and Joule heating are not considered while modelling the energy equation [29]. The thermo-physical properties of water and iron oxide are presented in Tab. 1.

\subsection{The mathematical equations}

The partial differential equations, which determine the conservation equations for mass, momentum and energy in dimensional form are expressed as the following:

$$
\begin{aligned}
& \frac{\partial u}{\partial x}+\frac{\partial v}{\partial y}=0 \\
& \rho_{f f}\left[u \frac{\partial u}{\partial x}+v \frac{\partial u}{\partial y}\right]=\left[-\frac{\partial p}{\partial x}+\mu_{f f}\left(\frac{\partial^{2} u}{\partial x^{2}}+\frac{\partial^{2} u}{\partial y^{2}}\right)+\right. \\
& \left.\sigma_{f f} B_{0}^{2}\left(v \sin \gamma \cos \gamma-u \sin ^{2} \gamma\right)\right] \\
& \rho_{f f}\left[u \frac{\partial v}{\partial x}+v \frac{\partial v}{\partial y}\right]=\left[-\frac{\partial p}{\partial y}+\mu_{f f}\left(\frac{\partial^{2} v}{\partial x^{2}}+\frac{\partial^{2} v}{\partial y^{2}}\right)+\right. \\
& \left.\sigma_{f f} B_{0}^{2}\left(u \sin \gamma \cos \gamma-v \cos ^{2} \gamma\right)\right] \\
& {\left[u \frac{\partial T}{\partial x}+v \frac{\partial T}{\partial y}\right]=a_{f f}\left(\frac{\partial^{2} T}{\partial x^{2}}+\frac{\partial^{2} T}{\partial y^{2}}\right)}
\end{aligned}
$$

The dimensional and dimensionless boundary conditions are presented in Tab. 2 and Tab. 3 respectively.

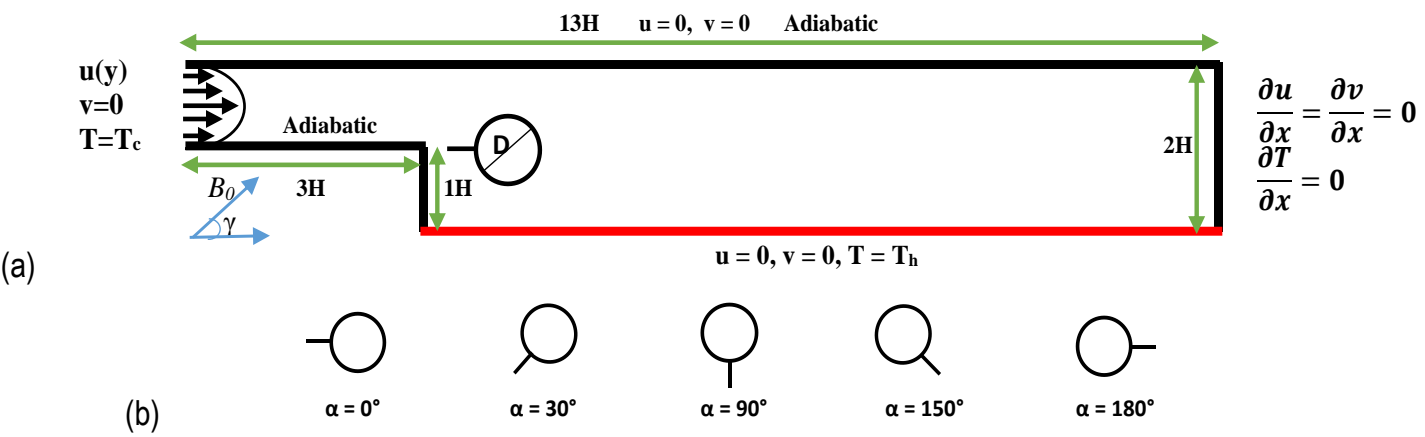

Fig. 1. Physical problem of backward facing step with boundary conditions (a), Fin position (b) 


\section{sciendo}

Meriem Toumi, Mohamed Bouzit, Fayçal Bouzit, Abderrahim Mokhefi

Tab. 1. Thermo-physical properties of Water and Iron Oxide

\begin{tabular}{|c|c|c|c|c|c|}
\hline & $\boldsymbol{\rho}\left(\mathbf{K g} / \mathbf{m}^{3}\right)$ & $\mathbf{C p}(\mathbf{J} / \mathbf{~ K g} . \mathbf{K})$ & $\mathbf{k}(\mathbf{W} / \mathbf{m} . \mathbf{K})$ & $\boldsymbol{\beta}(\mathbf{1} / \mathbf{K})$ & $\boldsymbol{\sigma}(\mathbf{1} / \mathbf{\Omega} . \mathbf{m})$ \\
\hline Distilled Water & 997.1 & 4,179 & 0.613 & $21 \times 10^{-5}$ & 0.05 \\
\hline Iron. Oxide $\mathrm{Fe}_{3} \mathbf{O}_{4}$ & 5,200 & 670 & 6 & $1.18 \times 10^{-5}$ & 25,000 \\
\hline
\end{tabular}

Tab. 2. Boundary conditions

\begin{tabular}{|l|l|}
\hline The inlet & $u=u(y), v=0, T=T_{c}$ \\
\hline The downstream bottom wall & $u=0, v=0, T=T_{h}$ \\
\hline $\begin{array}{l}\text { The outlet. } \boldsymbol{n} \text { is the surface normal } \\
\text { direction coinciding with the x axis at } \\
\text { the outlet }\end{array}$ & $\frac{\partial u}{\partial \boldsymbol{n}}=\frac{\partial v}{\partial \boldsymbol{n}}=\frac{\partial T}{\partial \boldsymbol{n}}=0$ \\
\hline $\begin{array}{l}\text { Other walls are adiabatic and the } \\
\text { velocity is no-slip. }\end{array}$ & $u=v=\frac{\partial T}{\partial \boldsymbol{n}}=0$ \\
\hline Finned cylinder is adiabatic & $\frac{\partial T}{\partial \boldsymbol{n}}=0$ \\
\hline Finned cylinder velocity components: & $u=0, v=0$ \\
\hline
\end{tabular}

\subsection{The dimensionless form equations}

Scales, which are used to obtain the dimensionless equations (5)-(8), are presented below:

$X=\frac{x}{H}, \quad U=\frac{u}{\bar{u}}, \quad \theta=\frac{T-T_{c}}{T_{h}-T_{c}}, \operatorname{Pr}=\frac{v_{f}}{\mathrm{a}_{f}}, H a=B_{0} H \sqrt{\frac{\sigma_{f f}}{\mu_{f f}}}$,

$Y=\frac{y}{H}, \quad V=\frac{v}{\bar{u}}, P=\frac{p}{\rho_{f f} \bar{u}^{2}}, R e=\frac{H \bar{u}}{v_{f}}$

$\frac{\partial V}{\partial X}+\frac{\partial V}{\partial Y}=0$

$U \frac{\partial U}{\partial X}+V \frac{\partial U}{\partial Y}=-\frac{\partial p}{\partial X}+\frac{1}{R e} \frac{\mu_{f f}}{\rho_{f f} v_{f}}\left(\frac{\partial^{2} U}{\partial X^{2}}+\frac{\partial^{2} U}{\partial Y^{2}}\right)$

$+\frac{\rho_{f}}{\rho_{f f}} \frac{\sigma_{f f}}{\sigma_{f}} \frac{H a^{2}}{R e}\left(V \sin \gamma \cos \gamma-U \sin ^{2} \gamma\right)$

$U \frac{\partial V}{\partial X}+V \frac{\partial V}{\partial Y}=-\frac{\partial p}{\partial Y}+\frac{1}{R e} \frac{\mu_{f f}}{\rho_{f f} v_{f}}\left(\frac{\partial^{2} V}{\partial X^{2}}+\frac{\partial^{2} V}{\partial Y^{2}}\right)+$

$\frac{\rho_{f}}{\rho_{f f}} \frac{\sigma_{f f}}{\sigma_{f}} \frac{H a^{2}}{R e}\left(U \sin \gamma \cos \gamma-V \cos ^{2} \gamma\right)$

$$
U \frac{\partial \theta}{\partial X}+V \frac{\partial \theta}{\partial Y}=\frac{1}{R e P r} \frac{a_{f f}}{a_{f}}\left(\frac{\partial^{2} \theta}{\partial X^{2}}+\frac{\partial^{2} \theta}{\partial Y^{2}}\right)
$$

Tab. 3. The dimensionless boundary conditions

\begin{tabular}{|l|l|}
\hline The inlet & $U=U(Y), V=0, \theta=0$ \\
\hline The downstream bottom wall & $U=0, V=0, \theta=1$ \\
\hline $\begin{array}{l}\text { The outlet. } \mathbf{n} \text { is the surface normal } \\
\text { direction coinciding with the } \mathrm{x} \text { axis at } \\
\text { the outlet }\end{array}$ & $\frac{\partial U}{\partial X}=\frac{\partial V}{\partial X}=\frac{\partial \theta}{\partial X}=0$ \\
\hline $\begin{array}{l}\text { Other walls are adiabatic and the } \\
\text { velocity is no-slip. }\end{array}$ & $U=V=\frac{\partial \theta}{\partial \boldsymbol{n}}=0$ \\
\hline cylinder-fin is adiabatic & $\frac{\partial \theta}{\partial \boldsymbol{n}}=0$ \\
\hline Finned cylinder velocity components & $U=0, V=0$ \\
\hline
\end{tabular}

\subsection{Thermo-physical properties of ferrofluid}

- Density: $\rho_{f f}=(1-\phi) \rho_{f}+\phi \rho_{p}$

- Thermal diffusivity: $a_{f f}=\frac{k_{f f}}{(\rho C p)_{f f}}$

- Electrical conductivity: $\delta_{f f}=\delta_{f}\left[1+\frac{3(\delta-1) \phi}{(\delta+2)-(\delta-1) \phi}\right]$, $\delta=\frac{\delta_{p}}{\delta_{f}}$

- Specific heat: $(\rho C p)_{f f}=(1-\phi)(\rho C p)_{f}+\phi(\rho C p)_{p}$

- Thermal expansion coefficient: $(\rho \beta)_{f f}=(1-$ $\phi)(\rho \beta)_{f}+\phi(\rho \beta)_{p}$

- Thermal conductivity: $\frac{k_{f f}}{k_{f}}=\frac{k_{p}+2 k_{f}-2 \phi\left(k_{f}-k_{p}\right)}{k_{p}+2 k_{f}+\phi\left(k_{f}-k_{p}\right)}$

- Dynamic viscosity: $\mu_{f f}=\frac{\mu_{f}}{(1-\phi)^{2.5}}$

Tab. 4. Convergence test of mesh

\begin{tabular}{|c|c|c|c|c|c|}
\hline Elements Number & 4375 & 13548 & 41558 & $\mathbf{8 7 3 2 5}$ & 172333 \\
\hline Time & $9 \mathrm{~s}$ & $19 \mathrm{~s}$ & $89 \mathrm{~s}$ & $\mathbf{2 4 0} \mathbf{s}$ & $467 \mathrm{~s}$ \\
\hline $\boldsymbol{N} \boldsymbol{u}_{\text {avg }}$ & 2.68620 & 2.66430 & 2.65797 & $\mathbf{2 . 6 5 8 2 1}$ & 2.65813 \\
\hline $\boldsymbol{\theta}_{\text {avg }}$ & 0.15511 & 0.15777 & 0.15888 & $\mathbf{0 . 1 5 8 9 8}$ & 0.15801 \\
\hline $\boldsymbol{V}_{\boldsymbol{a v g}}$ & 0.38551 & 0.39098 & 0.39421 & $\mathbf{0 . 3 9 4 8 2}$ & 0.39503 \\
\hline
\end{tabular}

The mesh test was done for a configuration where $\operatorname{Re}=100, \operatorname{Pr}=6.2, \mathrm{Ha}=25, \phi=0.05, \gamma=0^{\circ}$ and $\mathrm{a}=135^{\circ}$.

After performing the calculations on five grids, we noticed the values of $\boldsymbol{N} \boldsymbol{u}_{\boldsymbol{a v g}}, \boldsymbol{\theta}_{\boldsymbol{a v g}}$ and $\boldsymbol{V}_{\boldsymbol{a v g}}$ having too small a difference in each of the last two grids and thus we chose the penultimate grid which has the number of elements 87,325 .

\subsection{Compute of the average and local Nusselt number}

Convection is one of the methods of heat transfer. The term convection refers to the heat transfer processes that occur be- tween a surface and a moving fluid when they are at different temperatures. To measure the intensity of heat transfer in the fluid due to its movements and to characterise the heat exchange between the fluid and the wall, the Nusselt number is used.

The local Nusselt number on the hot wall is calculate as fol- 
lows:

$N u=\frac{h_{f f \cdot L}}{k_{f}}$

$h_{f f}$ is the heat transfer coefficient of ferrofluid. $h_{f f}=\frac{q_{w}}{T_{h}-T_{c}}$

$q_{w}$ stands for heat flux on the heated wall:

$q_{w}=-k_{f f}=\left.\frac{T_{h}-T_{c}}{L} \frac{\partial \theta}{\partial y}\right|_{y=0}$

$N u=\frac{k_{f f}}{k_{f}}\left(\frac{\partial \theta}{\partial Y}\right)$

The average Nusselt number on the hot wall is calculated as follows:

$N u_{\text {avg }}=\int_{0}^{L_{s}} N u d X$

$L_{s}$ is the total length of the heated part.

\section{NUMERICAL METHOD}

The partial differential equations in the dimensionless form provided in Eqs (5)-(8), which determine the conservation equations for mass, momentum and energy, as well as the boundary conditions which are associated with them, were solved using the finite element scheme based on the Galerkin method.

The computational domain or geometry is divided into several elements that represent the approximate geometry; several meshes are tested until the optimal one is found and used to start the numerical calculation and find the approximate results.

Triangular elements are used to discretise the computational domain. Five grids of different sizes were used until the optimal one could be chosen; the choices were among an enlarged mesh of 4,375 elements, a normal mesh of 13,548 elements, a fine mesh of 41,558 elements, and an extra fine mesh of 87,325 elements and an extremely fine mesh of 172,333 elements. To ensure mesh independence and to achieve optimal mesh distribution with accurate results and minimal computation time, the mesh containing 87,325 triangular elements were used to perform the computations. (Tab. 4)

\section{RESULTS AND DISCUSSION}

The main objective is to study the effect of fin position. Therefore, a numerical investigation is undertaken that concerns the forced convection of the flow of a ferrofluid on a backward facing step containing a single fin attached to a fixed cylinder in the presence of an external magnetic field with different inclinations.

In this study the control parameters such as Reynolds number $(\mathrm{Re})$, Hartmann number $(\mathrm{Ha})$, magnetic field tilt angle $(\mathrm{\gamma})$ and nanoparticle concentration $(\phi)$ are considered, and the fin position on the cylinder (a) is the key parameter that enables us to study its effect on the quality of heat transfer.

To carry out our numerical study, it is necessary to validate the results. Therefore, we need to compare the results obtained by the present numerical study with the results of [29]. The validation is done with the effect of the Hartmann number $(\mathrm{Ha}=0.0$ and $\mathrm{Ha}=100)$ on the isotherms and the average Nusselt number, for $\operatorname{Pr}=6.2, \operatorname{Re}=100, y=0^{\circ}$ and $\phi=0.05$ (Fig. 2).

The validation plot (Fig. 2) shows that our results are closely similar those of [29] and we find excellent consistency and very acceptable agreements.

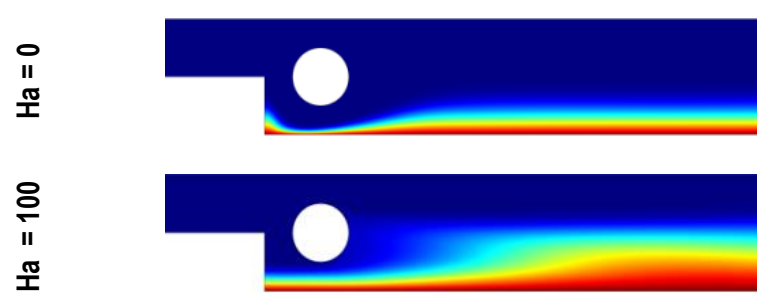

Present work
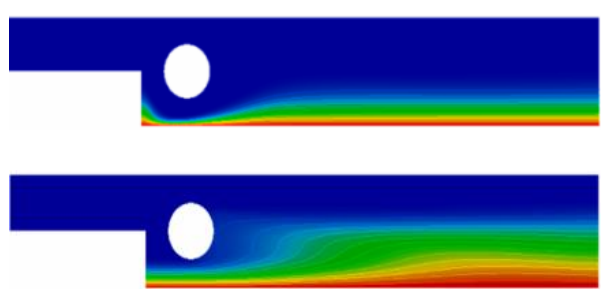

Hussain and Ahmed (2019)

Isotherms for $\operatorname{Pr}=6.2, \operatorname{Re}=100, y=0^{\circ}$ and $\phi=0.05$.

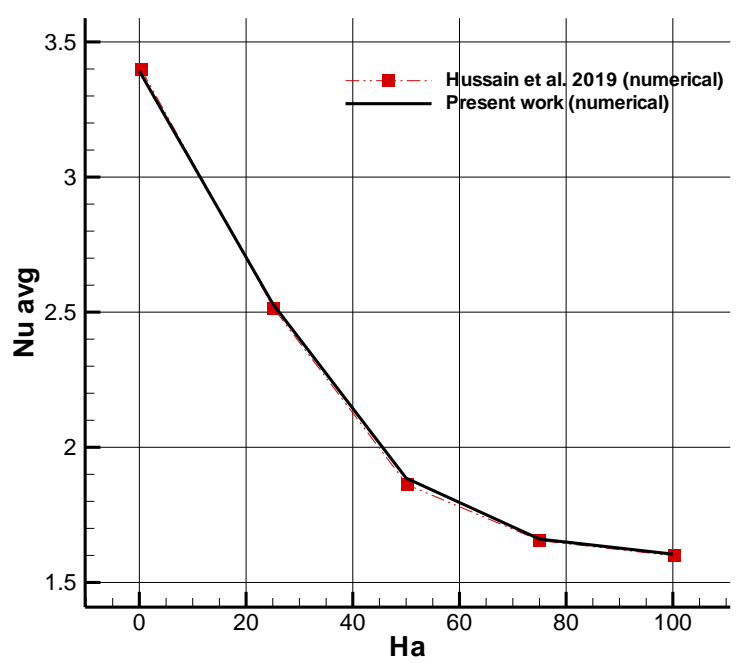

Fig. 2. Validation of results 
Different values of control parameter are taken, encompassing the Reynolds number (Re between 10 and 100), Hartmann number ( $\mathrm{Ha}$ between 0 and 100), nanoparticles concentration $(\varphi$ between 0 and 0.1 ), magnetic field inclination ( $\gamma$ between $0^{\circ}$ and $\left.90^{\circ}\right)$ and fin positions a $\left[0^{\circ}-180^{\circ}\right]$. Grashof and Richardson numbers are equal to zero and Prandtl number $=6.2$.

Simulations were carried out for several fin positions on the cylinder ranging from $0^{\circ}$ to $180^{\circ}$ in steps of 5.0. The results are therefore voluminous and for this reason it was chosen to present the streamline contours and isotherms for the most significant fin angle values $\left(\alpha=0^{\circ}, 30^{\circ}, 90^{\circ}, 150^{\circ}\right.$ and $\left.180^{\circ}\right)$.

Results obtained by numerical simulations for the study of forced convection of ferrofluid flow in a backward facing step geometry containing a single fin fixed on cylinder are analysed qualitatively through the contours of isotherms, and streamlines are presented in Figs 3-6; also, quantitative analysis is made by the calculation of the average Nusselt number, presented in Figs $7-10$, and of the local Nusselt number, presented in Figs 11-14.
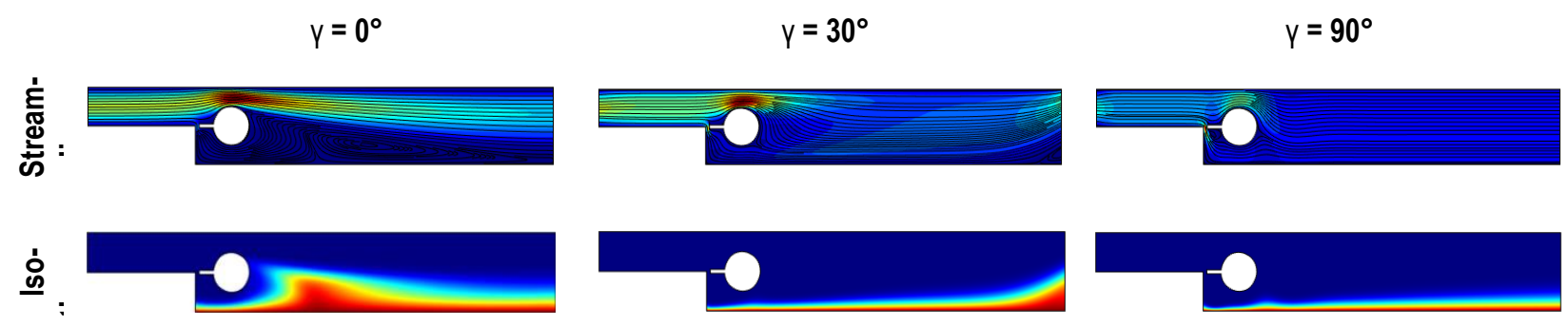

$\alpha=0^{\circ}$
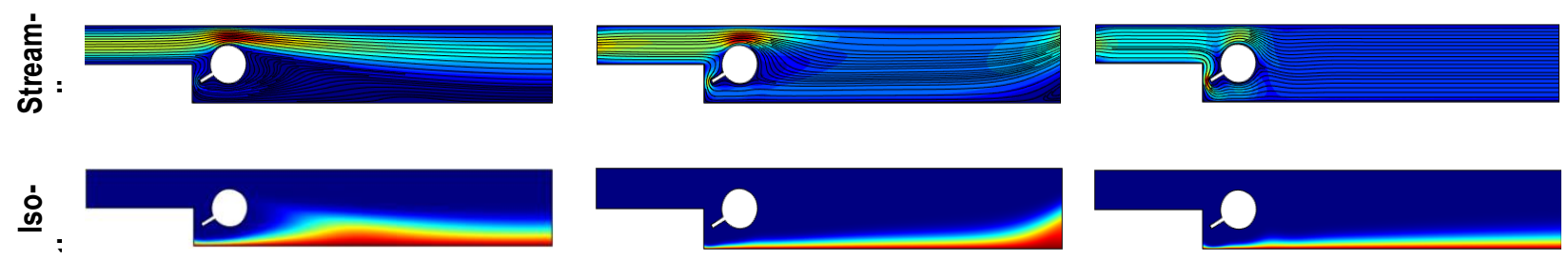

$\alpha=30^{\circ}$
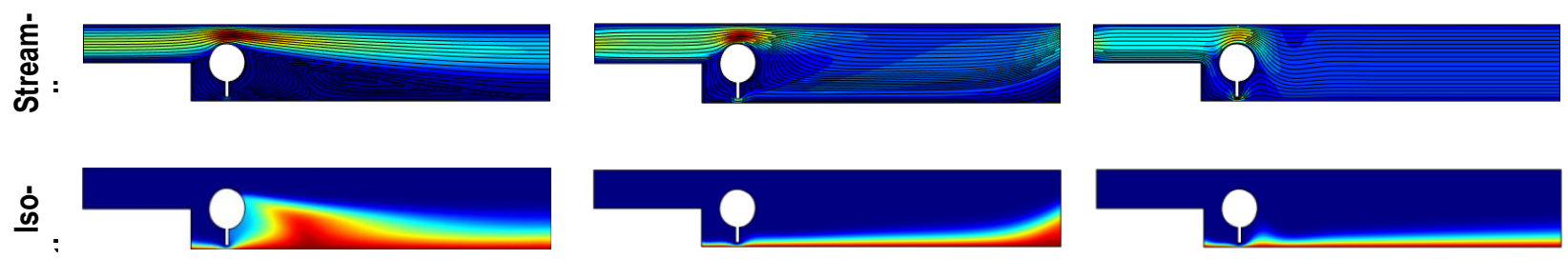

$$
\alpha=90^{\circ}
$$
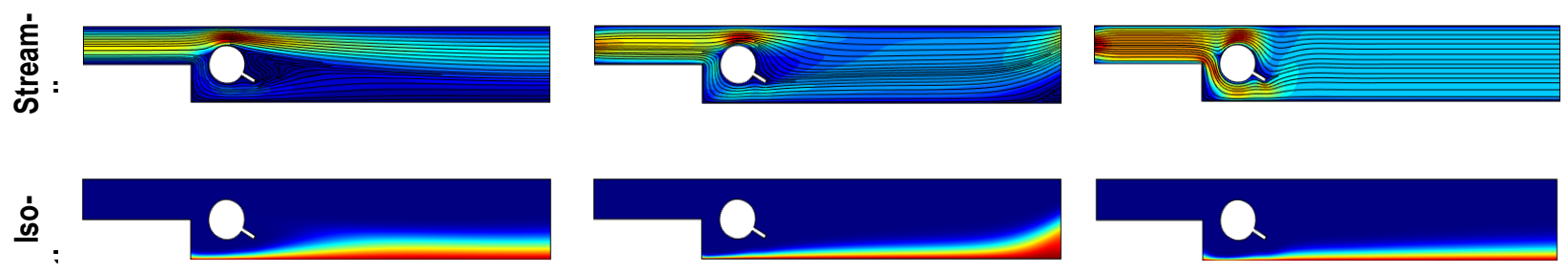

$$
\alpha=150^{\circ}
$$
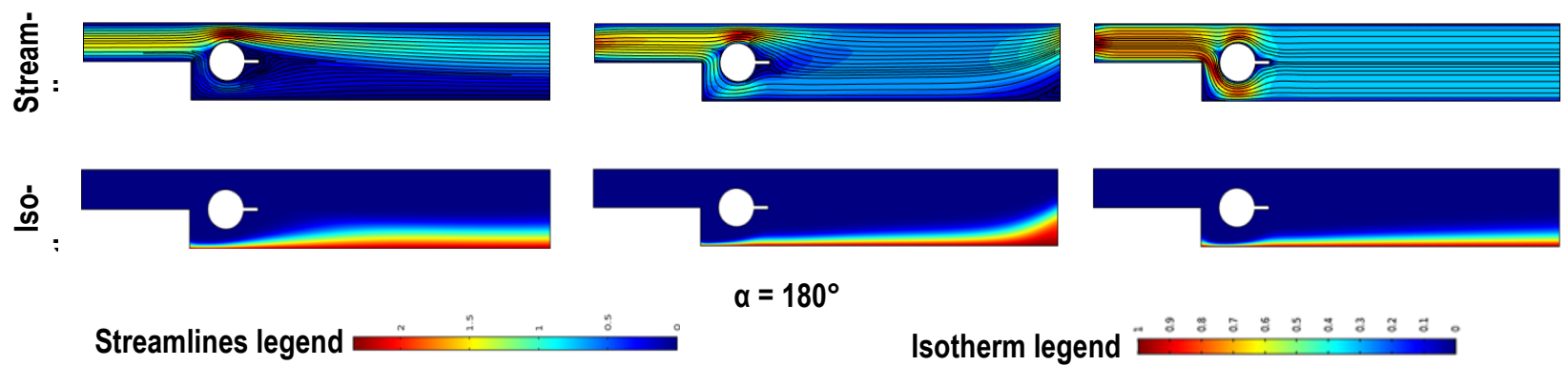

$$
\alpha=180^{\circ}
$$

Isotherm legend $\approx$ :

Fig. 3. Effect of Magnetic field inclination $y$ with different fin positions for $\operatorname{Pr}=6.2, \operatorname{Re}=100, \mathrm{Ha}=20$ and $\phi=0.04$

Fig. 3 highlights magnetic field inclination effect on the current lines' structure and on isotherms for different positions of fin cylinder, with $\operatorname{Pr}=6.2, \mathrm{Re}=100, \mathrm{Ha}=20$ and $\phi=0.04$. The contours in Fig. 3 are shown for magnetic field inclination cases $\left(\gamma=0^{\circ}\right.$, $30^{\circ}$ and $90^{\circ}$ ) and fin position $\left(\alpha=0^{\circ}, 30^{\circ}, 90^{\circ}, 150^{\circ}\right.$ and $\left.180^{\circ}\right)$. Weak forced convection exists when the magnetic field is horizon- 
tal $\left(\gamma=0^{\circ}\right)$ with $\left(\alpha=0^{\circ}, 30^{\circ}\right.$ and $\left.90^{\circ}\right)$; we notice in streamlines' images the presence of a vortex that slows down ferrofluid flow circulation, and we observe from isotherm contours that the amount of heat transmitted is small. For $\alpha=150^{\circ}$ and $\alpha=180^{\circ}$ the vortex is absent and the thermal layer in duct is thick. This leads us to conclude that the thermal heat transfer has improved due to fin position. When the magnetic field undergoes an inclination $\left(y=30^{\circ}\right.$ and $\left.y=90^{\circ}\right)$, a very significant improvement in heat transfer is manifested, especially for $\alpha=150^{\circ}$ and $\alpha=180^{\circ}$ where substantial thickness of the thermal layer is observed and the vortex is no longer present, which implies that the flow of ferrofluid starts to move towards the bottom wall. For $y=30^{\circ}$, the flow concentration is just above the cylinder and flow lines are almost straight; and for $\mathrm{y}=90^{\circ}$, the ferrofluid concentration is around all the obstacles (cylinder and fin); and at the top and bottom, the flow lines corresponding to the ferrofluid are parallel. For $\left(\alpha=0^{\circ}\right.$, $30^{\circ}$ and $90^{\circ}$ ) the transfer remains less efficient due to the effect of fin position.

The presence of the external magnetic field leads to a decrease in the heat transfer quality due to Lorentz force, which slows down the ferrofluid movement. When the magnetic field is inclined, forced convection is in enhancement. As a result, Lorentz force, in itself, depends on the angle between magnetic field and ferrofluid velocity.

The effect of magnetic field inclination $\left(\gamma=30^{\circ}\right.$ and $\left.90^{\circ}\right)$ and fin position $\left(\alpha=150^{\circ}\right.$ and $\left.180^{\circ}\right)$ on the heat transfer allows a gain in transfer rate compared to the case of the horizontal magnetic field.

$$
\operatorname{Re}=10
$$$$
\text { ह }
$$
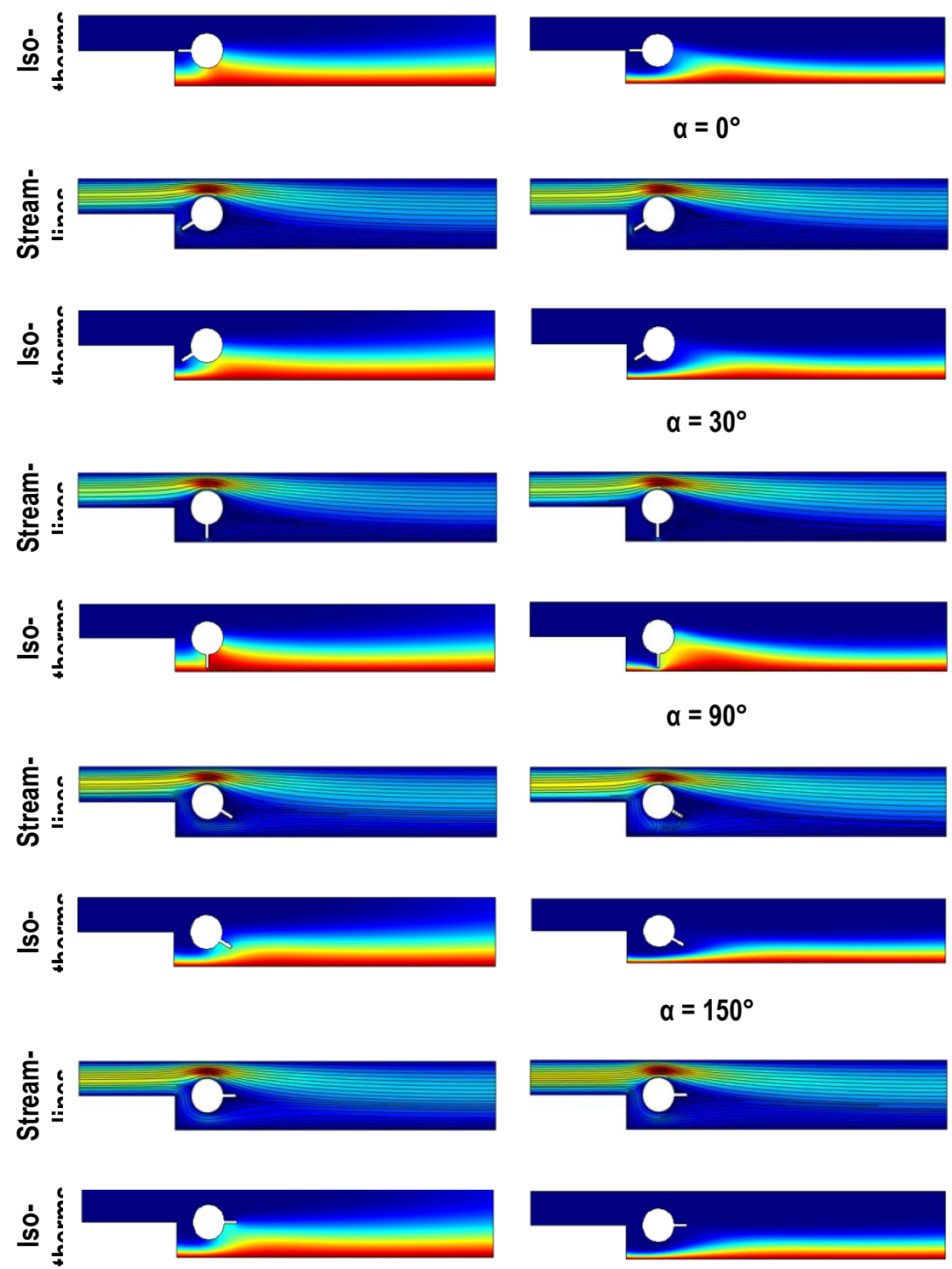

$\alpha=0^{\circ}$

$$
\alpha=30^{\circ}
$$

$$
\alpha=90^{\circ}
$$

$$
\alpha=150^{\circ}
$$
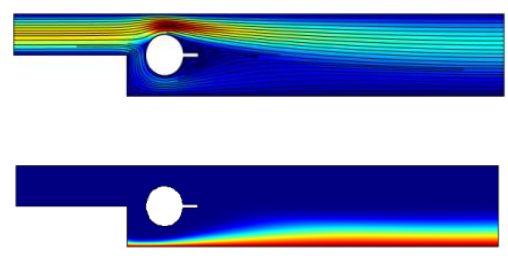

$\operatorname{Re}=100$
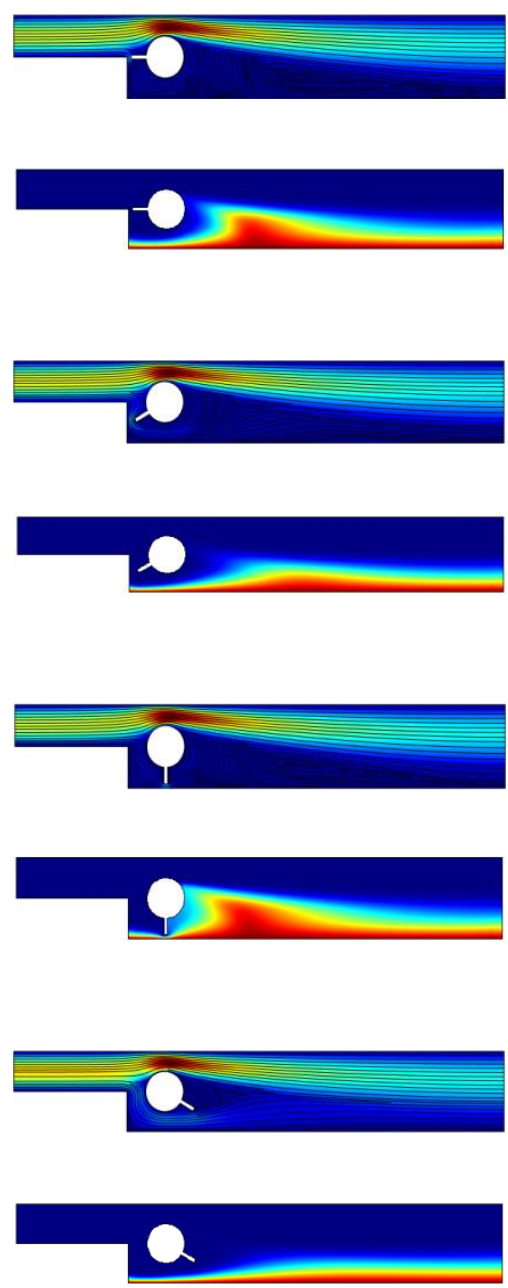

$$
\alpha=180^{\circ}
$$

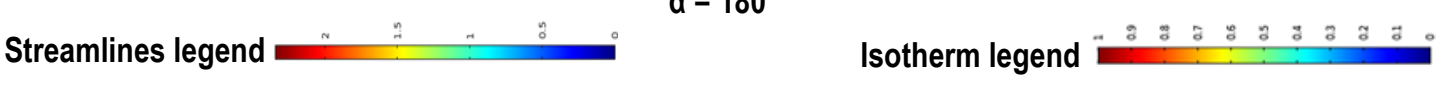

Fig. 4. Effect of Reynolds number Re with different fin positions for $\operatorname{Pr}=6.2, y=0^{\circ}, \mathrm{Ha}=20$ and $\phi=0.04$ 
Concerning the influence of Reynolds number on the streamlines and isotherms, from Fig. 4 it is evident that for $\mathrm{Re}=10$ with all fin positions $\left(\alpha=0^{\circ}, 30^{\circ}, 90^{\circ}, 150^{\circ}\right.$ and $\left.180^{\circ}\right)$, the flow is slow and the thermal layer is thin, which results in poor heat transfer quality. This effect is attributable to the fact that for a low value of Reynolds number, inertial forces related to velocities are negligible and viscous forces are high, which explains a slow motion of ferrofluid. As the Reynolds number increases, the velocity inertia forces also increase and therefore the motion of the ferrofluid starts to become faster. So, for $\operatorname{Re}=50$ and $\operatorname{Re}=100$ with $\left(\alpha=0^{\circ}, 30^{\circ}\right.$ and $\left.90^{\circ}\right)$, the heat transfer quality has improved slightly and it is more efficient when $\left(a=150^{\circ}\right.$ and $\left.180^{\circ}\right)$ since the thermal layer has become thick.

It can be concluded that as Reynolds number increases, heat transfer improves and fin position still has its effect on the improvement.
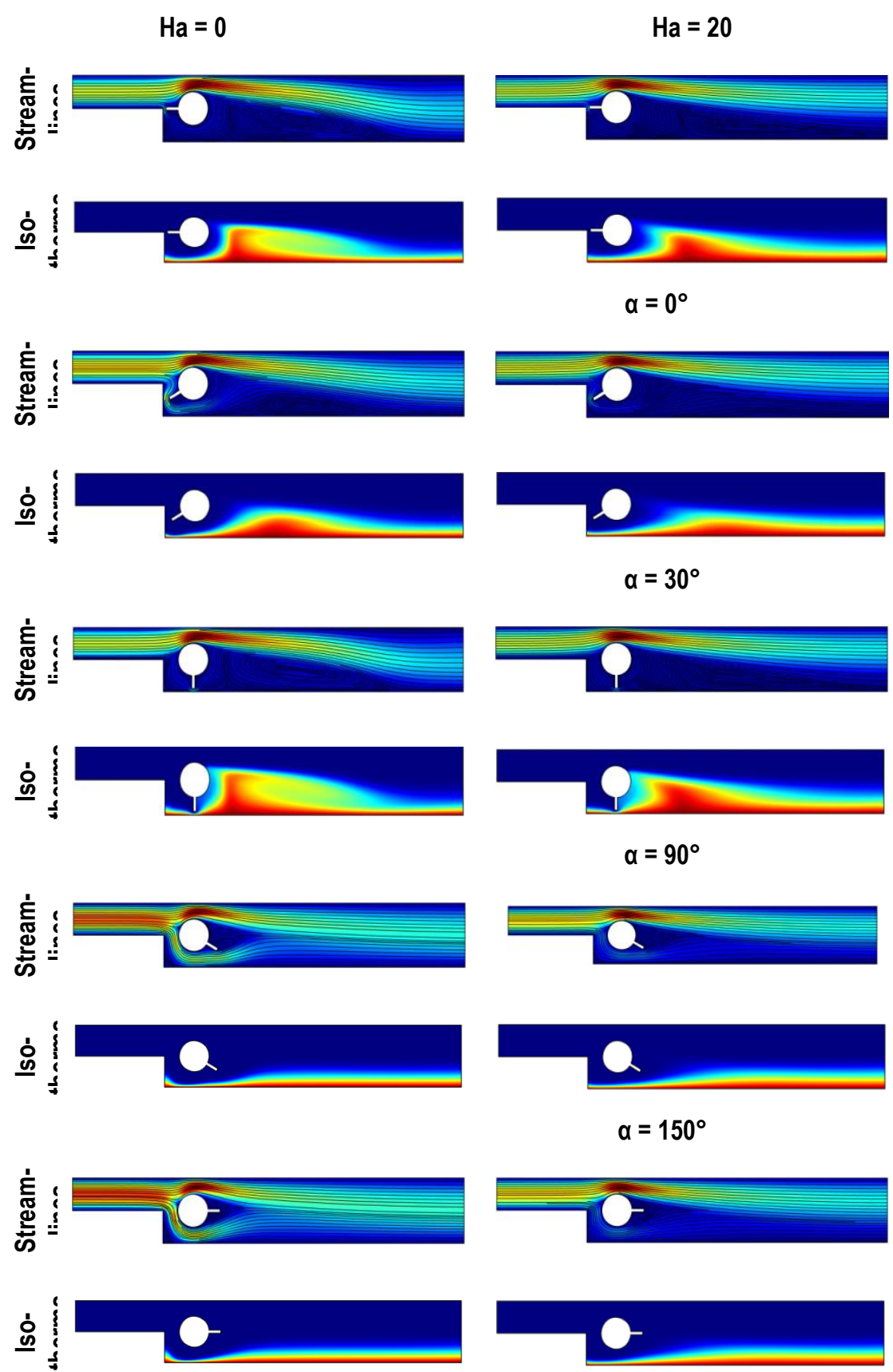

Streamlines legend $\alpha=30^{\circ}$

$\alpha=90^{\circ}$

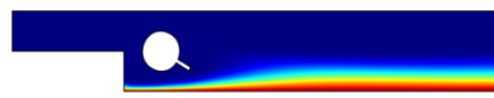

$\alpha=150^{\circ}$

$\mathrm{Ha}=20$

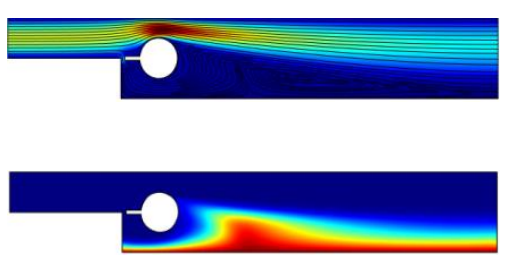

$$
\alpha=0^{\circ}
$$
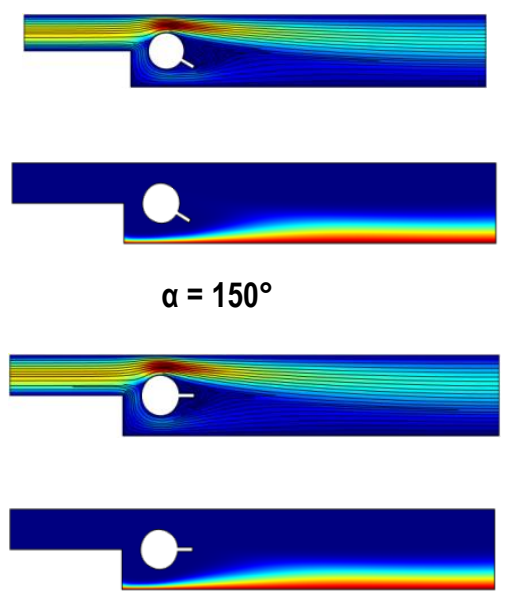

$\alpha=180^{\circ}$
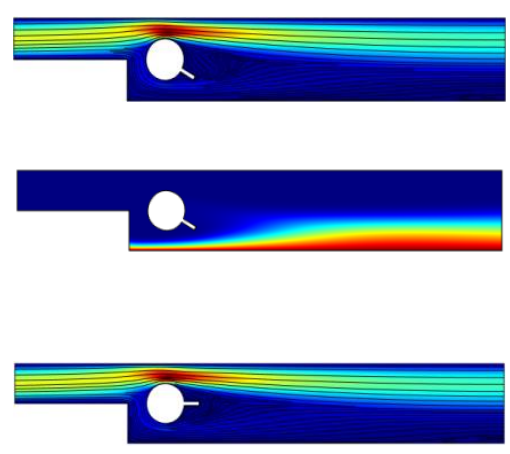

$\mathrm{Ha}=\mathbf{4 0}$
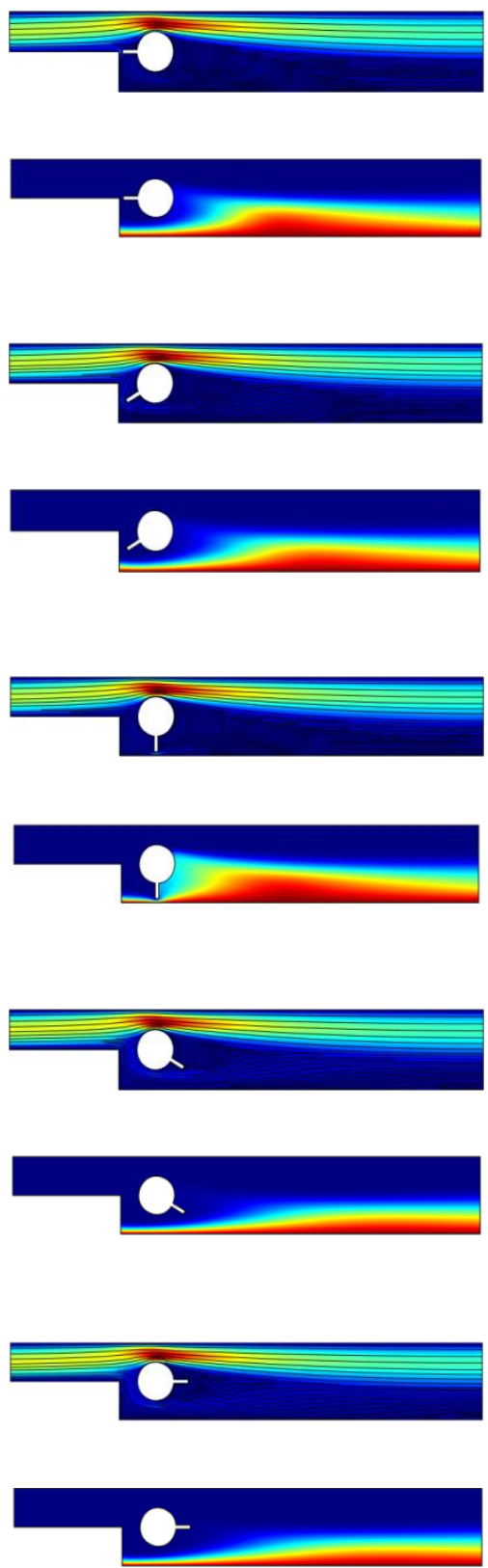

Fig. 5. Effect of Hartmann number Ha with different fin positions for $\operatorname{Pr}=6.2, y=0^{\circ}, \operatorname{Re}=100$ and $\phi=0.04$

The dimensionless Hartmann number represents the external magnetic field strength. Hartmann number $(\mathrm{Ha}=0,20$ and 100) and fin position $\left(\alpha=0^{\circ}, 30^{\circ}, 90^{\circ}, 150^{\circ}\right.$ and $\left.180^{\circ}\right)$ have an effect on streamlines and temperature field for $\operatorname{Pr}=6.2, y=0^{\circ}, \operatorname{Re}=100$ and $\phi=0.04$ ), as shown in Fig. 5 . 
Fig. 5 shows that in the absence of magnetic field $\mathrm{Ha}=0$ with fin positions $\left(a=0^{\circ}, 30^{\circ}\right.$ and $\left.90^{\circ}\right)$, it is observed that in the streamline images a vortex that forms behind the obstacle causes a slowing down of fluid motion; so, on temperature field contours the thermal layer is reduced, reflecting poor forced convection. For $\left(\alpha=150^{\circ}\right.$ and $\left.180^{\circ}\right)$ streamlines are straight and parallel and the flow motion is therefore fast, and thermal layer is thin; hence, good forced convection is available for those fin positions with $\mathrm{Ha}=0.0$.

$\varphi=0$
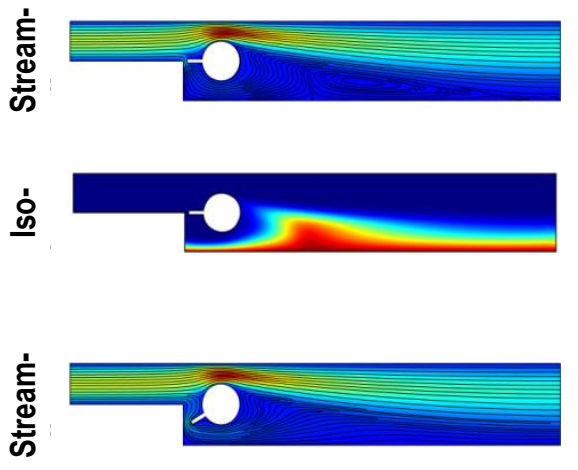

으
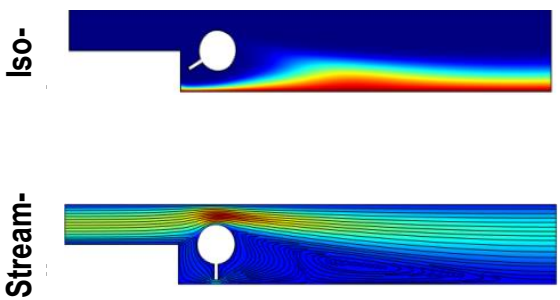

으
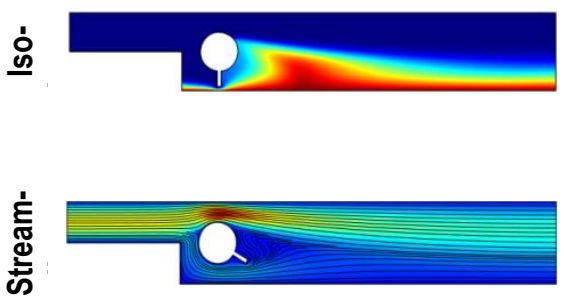

\section{으}
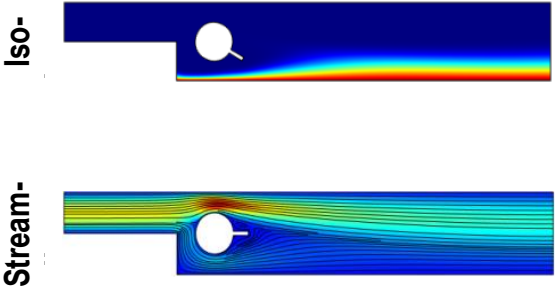

으

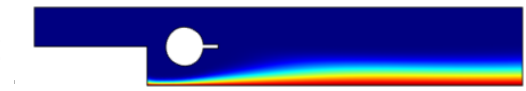

$\varphi=0.02$
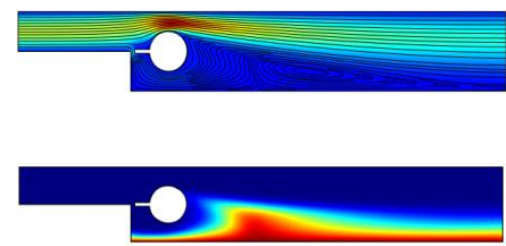

$\alpha=0^{\circ}$
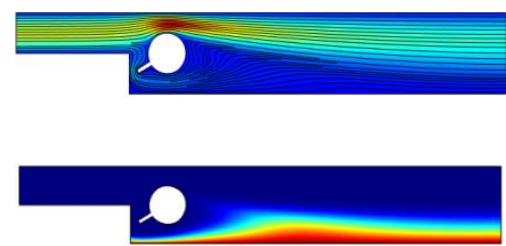

$\alpha=30^{\circ}$
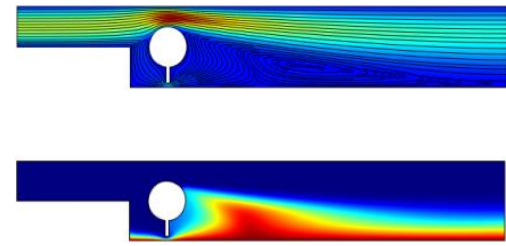

$\alpha=90^{\circ}$
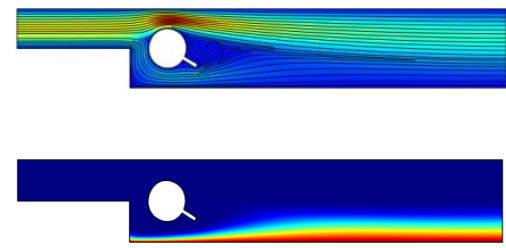

$\alpha=150^{\circ}$
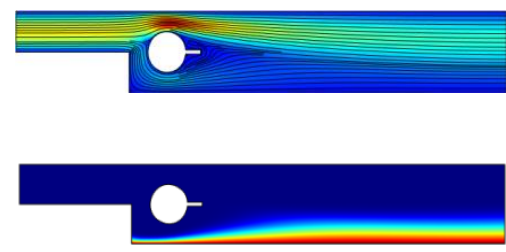

$$
\alpha=180^{\circ}
$$

Streamlines legend

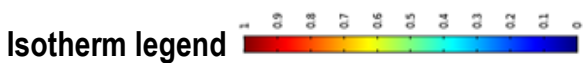

Fig. 6. Effect of nanoparticles concentration $\phi$ with different fin positions for $\operatorname{Pr}=6.2, y=0^{\circ}, \mathrm{Re}=100$ and $\mathrm{Ha}=20$

Fig. 6 shows the effect of nanoparticles' concentration and fin position on the structure of streamlines and isotherms, for $\mathrm{Pr}=6.2, \mathrm{y}=0^{\circ}, \mathrm{Re}=100$ and $\mathrm{Ha}=20$. To illustrate the streamlines and isotherms and to present concentration of the magnetite
$\mathrm{Fe}_{3} \mathrm{O}_{4}$ effect, we have chosen $(\phi=0.0,0.02$ and 0.04$)$ among the set of values used in numerical simulation.

It is observed that insertion of $\mathrm{Fe}_{3} \mathrm{O}_{4}$ nanoparticles in a base fluid in the presence of moderate magnetic field $\mathrm{Ha}=20$ contrib- 
utes to improvement of heat transfer compared to cases of pure distilled and ionised water fluid. Heat transfer quality increases with increasing nanoparticles' concentration under the thermal conductivity effect of the ferrofluid. The position of the fin on the cylinder still has its effect on the quality of heat transfer. For

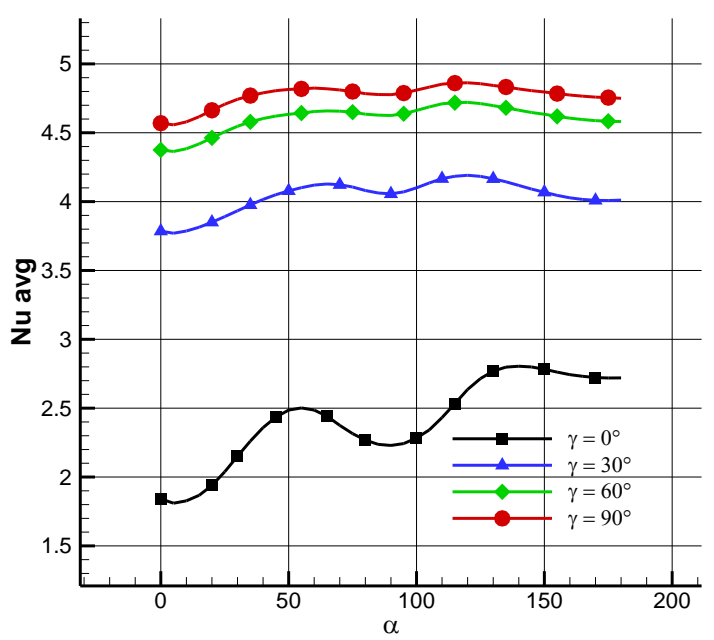

Fig. 7. Effect of magnetic field inclination with different fin positions on average Nusselt number for $\operatorname{Pr}=6.2, \mathrm{Re}=100, \mathrm{Ha}=20$ and $\phi=0.04$

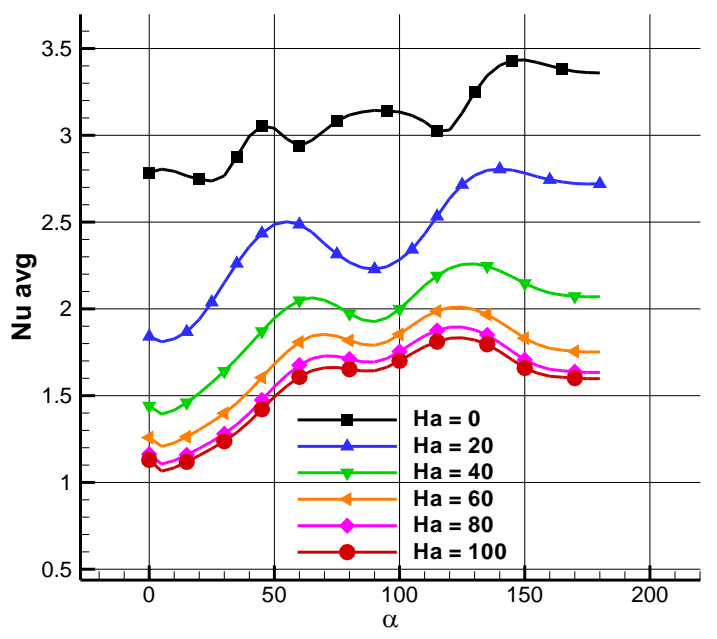

Fig. 9. Effect of Hartmann number with different fin positions on average Nusselt number for $\operatorname{Pr}=6.2, y=0^{\circ}, \operatorname{Re}=100$ and $\phi=0.04$

In this section, the analysis of the results of average Nusselt number variation as a function of different parameters (magnetic field inclination, Reynolds number, Hartmann number and nanoparticles' concentration) and fin position on cylinder is provided. Study of ferrofluid movement behaviour and the quality of heat transfer in duct is made for different values of these parameters.

The variation of the average Nusselt number as a function of the magnetic field inclination $y$ with variation of fin position for $\operatorname{Pr}=6.2, \operatorname{Re}=100, \mathrm{Ha}=20$ and $\phi=0.04$ is presented in Fig. 7 . Fig. 7 shows that the best heat transfer rate by forced convection is at $y=90^{\circ}$ with $\alpha=150^{\circ}$ such that the average Nusselt reaches its maximum value of 4.7965 , while it takes a smaller value when $y=0^{\circ}$ with $a=0^{\circ}$. So, to conclude, increasing $y$ increases the average Nusselt number due to the fact that Lorentz force, in itself, depends on the angle between magnetic field and ferrofluid flow velocity, with a better fin position $\alpha=150^{\circ}$. The effect on fin $\left(\alpha=0^{\circ}, 30^{\circ}\right.$ and $\left.90^{\circ}\right)$, the thermal layer is thin, indicating a degraded heat transfer due to these positions. For $\left(\alpha=150^{\circ}\right.$ and $180^{\circ}$ ) forced convection is improved because the thermal layer has become thick and streamlines are parallel.

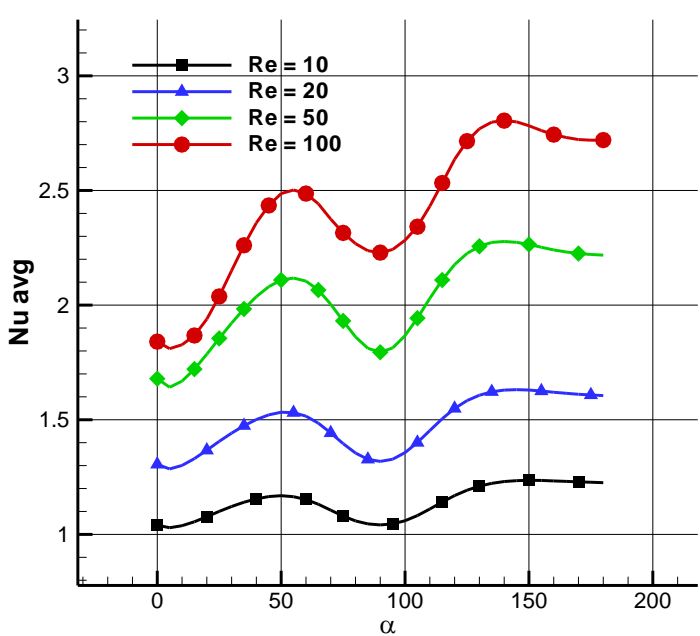

Fig. 8. Effect of Reynolds number with different fin positions on average Nusselt number for $\operatorname{Pr}=6.2, y=0^{\circ}, \mathrm{Ha}=20$ and $\phi=0.04$

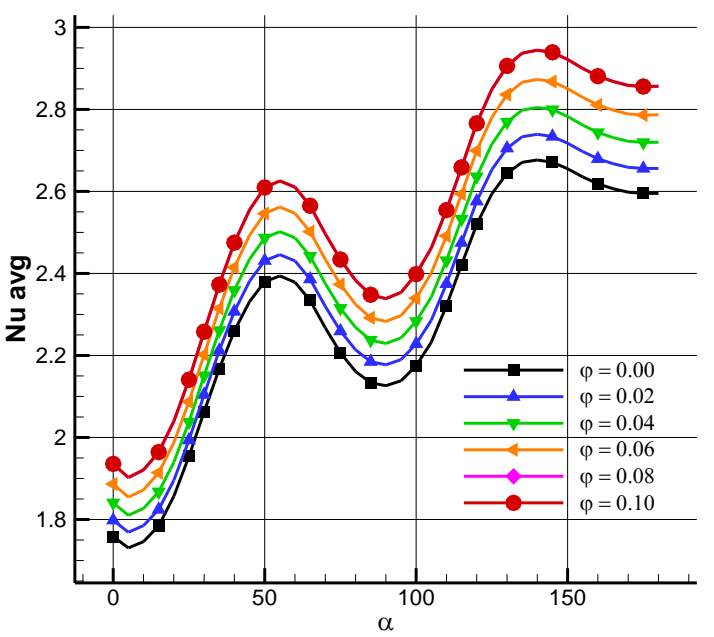

Fig. 10. Effect of nanoparticles concentration with different fin positions on average Nusselt number for $\operatorname{Pr}=6.2, \mathrm{y}=0^{\circ}$, $\mathrm{Re}=100$ and $\mathrm{Ha}=20$

position and Reynolds number on the average Nusselt number is presented in Fig. 8 for $\mathrm{Pr}=6.2, \mathrm{y}=0^{\circ}, \mathrm{Ha}=20$ and $\phi=0.04$. The highest average Nusselt value achieved 2.7825 for $\mathrm{Re}=100$ with $a=150^{\circ}$, while for the lowest Reynolds value $(\operatorname{Re}=10)$ with $a=0^{\circ}$, the average Nusselt takes the lowest value which attains 1.0404 , resultant to which the heat transfer rate was reduced. Therefore, as the Reynolds number increases, average Nusselt number also increases, because inertial forces make the ferrofluid flow faster. Fig. 9 displays the results of the average Nusselt number variation as a function of Hartmann number and fin position on cylinder for $\operatorname{Pr}=6.2, y=0^{\circ}, \operatorname{Re}=100$ and $\phi=0.04$. For $\mathrm{Ha}=0$ with $\mathrm{a}=150^{\circ}$, the average Nusselt number reaches a high value which corresponds to 3.4340 . On the other hand, $\mathrm{Ha}=100$ with $a=0^{\circ}$ shows the lowest mean Nusselt value which attains to 1.2585. So, increasing Hartmann number leads to decrease in the average Nusselt number because of Lorentz force, which slows 
down the flow. To perceive the effect of nanoparticle concentration and fin position on heat transfer rate improvement for $\mathrm{Pr}=6.2, \mathrm{y}=0^{\circ}, \mathrm{Re}=100$ and $\mathrm{Ha}=20$, we present Fig. 10. The results show that the increase in $\phi$ generates an improvement in heat transfer rate due to thermal conductivity of ferrofluid. The

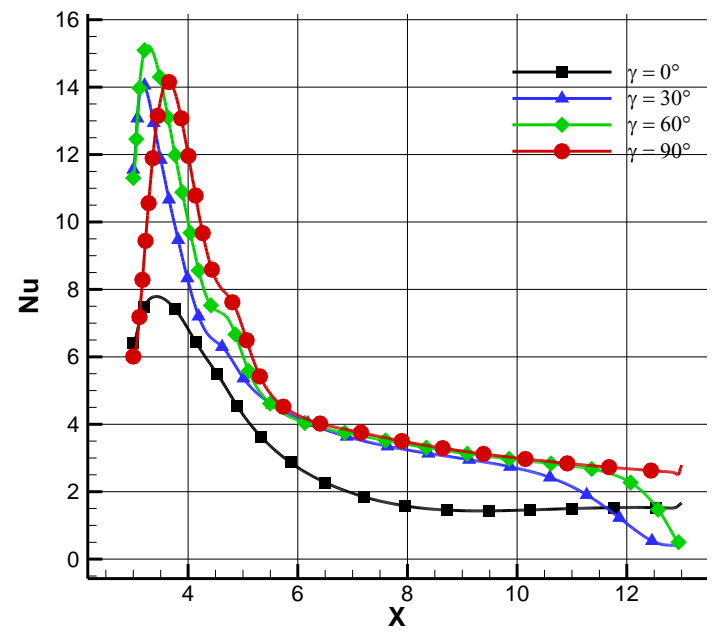

Fig. 11. Effect of magnetic field inclination on local Nusselt number along the heated wall for $\operatorname{Pr}=6.2$, $\mathrm{Re}=100, \mathrm{Ha}=20, \phi=0.04$ and $\mathrm{a}=150^{\circ}$

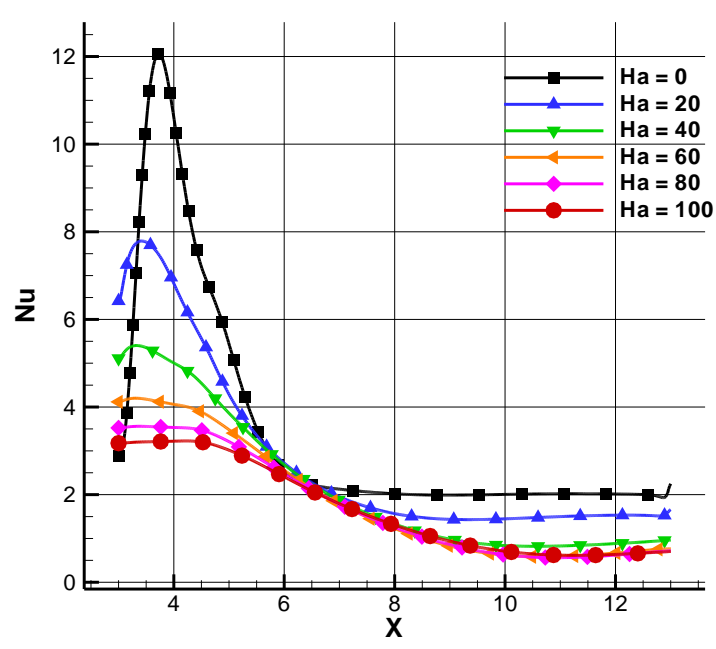

Fig. 13. Effect of Hartmann number on local Nusselt number along the heated wall for $\operatorname{Pr}=6.2, y=0^{\circ}, \operatorname{Re}=100$, $\phi=0.04$ and $\alpha=150^{\circ}$

Figs 11-14 present the evaluation of the local Nusselt number as a function of all the control parameters used in the present study (magnetic field inclination, Reynolds number, Hartmann number and nanoparticle concentration) with the most favoured fin position $a=150^{\circ}$. The local Nusselt number is calculated along the hot bottom wall to show the development of heat transfer at this wall.

For all four graphs in Figs 11-14, it is observed that the local Nusselt number distribution is maximum in the vicinity of the obstacle (finned cylinder) and the backward facing step (from $X=3$ up to $X=6$ ); thus this part corresponds to a strong temperature gradient, causing cooling of the heated plate. After the obstacle $(X>6)$, the local Nusselt number starts to decrease and takes minimum values as the displacement towards the duct exits; so, the temperature gradient is low. highest value of average Nusselt number was obtained when $\left(\phi=0.1\right.$ with $\left.\alpha=150^{\circ}\right)$ and the smallest value of average Nusselt number corresponds to the case $\left(\phi=0.0\right.$ with $\left.\alpha=0^{\circ}\right)$.

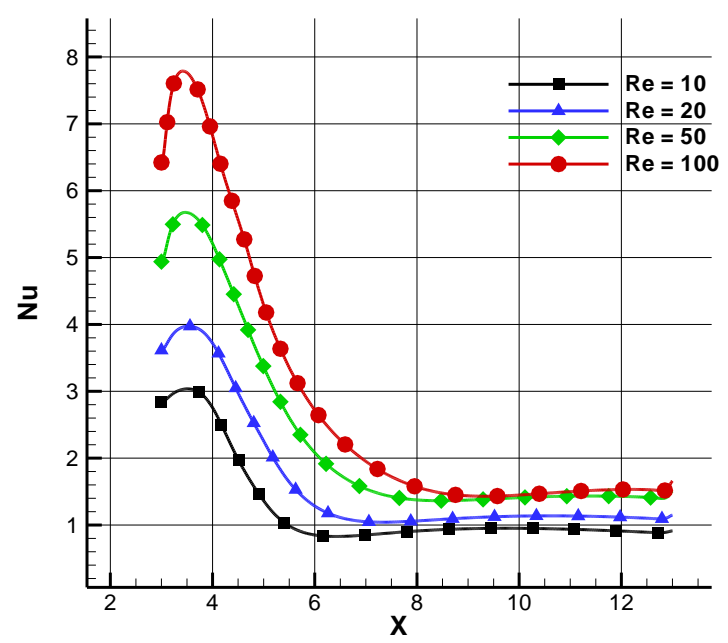

Fig. 12. Effect of Reynolds number on Local Nusselt number along the heated wall for $\operatorname{Pr}=6.2, y=0^{\circ}$, $\mathrm{Ha}=20, \phi=0.04$ and $\mathrm{a}=150^{\circ}$

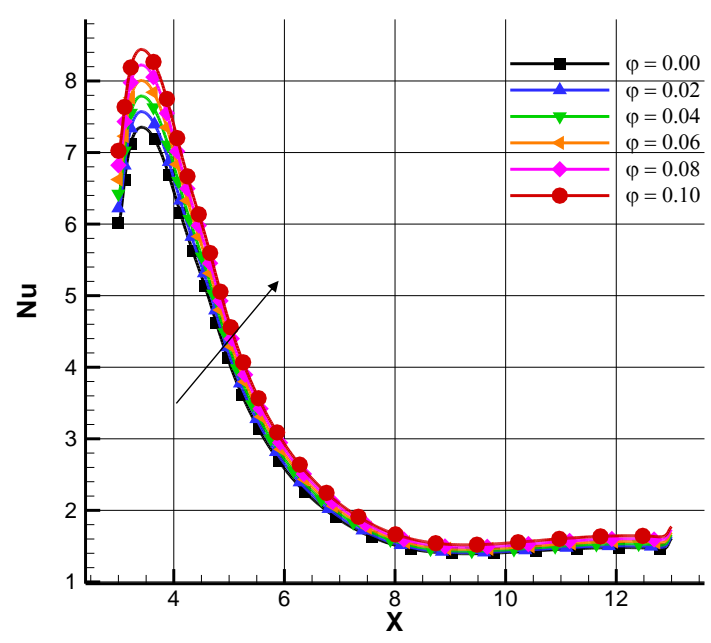

Fig. 14. Effect of nanoparticles concentration on local Nusselt number along the heated wall for $\mathrm{Pr}=6.2, \mathrm{Ha}=20$, $y=0^{\circ}, \operatorname{Re}=100$ and $\alpha=150^{\circ}$

From Fig. 13, which illustrates the effect of the Hartmann number on the variations of the local Nusselt number along the hot wall, it is observed that as the Hartmann number increases, the peaks of the local Nusselt number decrease. In Figs 11, 12 and 14, it is observed that as the values of the parameters (magnetic field inclination, Reynolds number and nanoparticle concentration) increase, the local Nusselt number increases.

\section{CONCLUSIONS}

A numerical study of the forced convection of ferrofluid on a backward facing step containing a finned cylinder with different fin positions on cylinder was conducted by changing angles of inclination of the magnetic field. The partial differential equations, 
which determine the conservation equations for mass, momentum and energy, were solved using finite element scheme based on Galerkin method. Analysis of heat transfer characteristics by forced convection was made by considering different values of Reynolds number, Hartmann number, nanoparticles' concentration and magnetic field inclinations, and by taking several fin position angles (between $0^{\circ}$ and $180^{\circ}$ ).

Compared to previously published research results, we note excellent consistency and very acceptable agreements. We can summarise our findings as follows.

- Magnetic field inclination has an effect on heat transfer quality; Nusselt number is more important in the vertical direction than in the horizontal one.

\section{NOMENCLATURE:}

Bo Magnetic field strength (Tesla)

$H \quad$ heat transfer coefficient $\left(\mathrm{W} / \mathrm{m}^{2} \mathrm{~K}\right)$

$\mathrm{Ha} \quad$ Hartmann number, $B_{0} H \sqrt{\frac{\sigma_{f f}}{\mu_{f f}}}$

$K \quad$ thermal conductivity $(\mathrm{W} / \mathrm{m} \mathrm{K})$

$H \quad$ inlet step height, $(\mathrm{m})$

$n$ normal coordinate

$\mathrm{Nu} \quad$ local Nusselt number

$N u_{\text {avg }}$ averaged Nusselt number

$p \quad$ pressure $(\mathrm{Pa})$

$P \quad$ non-dimensional pressure

Pr Prandtl number $\left(\frac{v_{f}}{a_{f}}\right)$

Re Reynolds number $\left(\frac{\boldsymbol{H} \bar{u}}{v_{f}}\right)$

$T \quad$ temperature $(\mathrm{K})$

Cp Thermal specific heat $(\mathrm{J} / \mathrm{Kg} \mathrm{K})$

$u, v \quad \mathrm{X}-\mathrm{y}$ velocity components $(\mathrm{m} / \mathrm{s})$

$U, V \quad$ dimensionless velocity components

$x, y \quad$ Cartesian coordinates (m)

$X, Y \quad$ dimensionless coordinates
- The results show that when magnetic particles' concentration of ferrofluid increases, the thermal diffusivity also increases.

- The heat transfer rate increases as the Reynolds number increases too.

- When the Hartmann number increases, the heat transfer rate is reduced.

However, fin position on fixed cylinder has the maximum influence on heat transfer quality. The best fin position is at $\left(\alpha=150^{\circ}\right)$, which gives the best Nusselt number; however, the fin position at $\left(a=0^{\circ}\right)$ remains an unfavourable case that gives the lowest Nusselt values.

\section{Greek symbols}

nanoparticle concentration

thermal diffusivity $\left(\mathrm{m}^{2} / \mathrm{s}\right)$

expansion coefficient $(1 / K)$

inclination angle of magnetic field

dimensionless temperature $\frac{T-T_{C}}{T_{h}-T_{C}}$

kinematic viscosity $\left(\mathrm{m}^{2} / \mathrm{s}\right)$

density of the fluid $\left(\mathrm{kg} / \mathrm{m}^{3}\right)$

electrical conductivity $(\mu \mathrm{S} / \mathrm{cm})$

dynamic viscosity, $\mathrm{N} \mathrm{s} / \mathrm{m}^{2}$

fin position

\section{Subscripts}

c Cold

h Hot

avg average

ff ferrofluid

\section{REFERENCES}

1. Erturk E. Numerical solutions of 2-D steady incompressible flow over a backward-facing step, Part I: High Reynolds number solutions. Computers \& Fluids. 2008; 37:633-655.

2. Ternik P. New contributions on laminar flow of inelastic nonNewtonian fluid in the two-dimensional symmetric expansion: Creeping and slowly moving flow conditions. J Non-Newtonian Fluid Mech. 2010; 165:1400-1411.

3. Xie WA, Xi GN. Fluid flow and heat transfer characteristics of separation and reattachment flow over a backward-facing step. Int $\mathrm{J}$ of refrigeration. 2017; 74:177-189.

4. Lan H, Armaly BF, Drallmeier JA. Three-dimensional simulation of turbulent forced convection in a duct with backward-facing step. Int $J$ of Heat and Mass Transfer. 2009; 52:1690-1700.

5. Khanafer K, Al-Azmi B, Al-Shammari A, Pop I. Mixed convection analysis of laminar pulsating flow and heat transfer over a backwardfacing step. Intl J of Heat and Mass Transfer. 2008; 51:5785-5793.

6. Barrios-Pina H, Viazzo S, Rey C. A numerical study of laminar and transitional mixed convection flow over a backward-facing step. Computers \& Fluids. 2012; 56:77-91.

7. Zhao P, Ge Z, Zhu J, Liu J, Ye M. Quasi-direct numerical simulation of forced convection over a backward facing step: Effect of Prandtl number. Nuclear Engineering and Design. 2018; 335:374-388.
8. Kumar S, Vengadesan S. The effect of fin oscillation in heat transfer enhancement in separated flow over a backward facing step. Int $\mathrm{J}$ of Heat and Mass Transfer. 2019; 128:954-963.

9. Kumar A, Dhiman AK. Effect of a circular cylinder on separated forced convection at a backward-facing step. Int J of Thermal Sciences. 2012; 52:176-185.

10. Hussain S, Ahmed SE, Akbar T. Entropy generation analysis in MHD mixed convection of hybrid nanofluid in an open cavity with a horizontal channel containing an adiabatic obstacle. Int $\mathrm{J}$ of Heat and Mass Transfer. 2017; 114:1054-1066

11. Kherbeet ASh, Mohammed HA, Munisamy KM, Salman BH. The effect of step height of microscale backward-facing step on mixed convection nanofluid flow and heat transfer characteristics. Int $\mathrm{J}$ of Heat and Mass Transfer. 2014; 68:554-566.

12. Abu-Nada E. Application of nanofluids for heat transfer enhancement of separated flows encountered in a backward facing step. Int $\mathrm{J}$ of Heat and Fluid Flow. 2008; 29:242-249.

13. Kherbeet AS, Mohammed HA, Salman BH. The effect of nanofluids flow on mixed convection heat transfer over microscale backwardfacing step. Int J of Heat and Mass Transfer. 2012; 55:5870-5881.

14. Hussain S. Finite Element Solution for MHD Flow of Nanofluids with Heat and Mass Transfer through a Porous Media with Thermal Radiation, Viscous Dissipation and Chemical Reaction Effects. Advances in Applied Mathematics and Mechanics Adv. Appl. Math. Mech. 2017; 9(4):904-923. 
15. Nath R, Krishnan M. Numerical study of double diffusive mixed convection in a backward facing step channel filled with Cu-water nanofluid. Int J of Mechanical Sciences. 2019; 153(154):48-63.

16. Lv J, Hu C, Bai M, Li L, Shi L, Gao D. Visualization of $\mathrm{SiO}_{2}$-water nanofluid flow characteristics in backward facing step using PIV. Experimental Thermal and Fluid Science. 2019; 101:151-159.

17. Hilo AK, Abu Talib A, Iborra AA, Hameed Sultan MT, Abdul Hamid MF. Experimental study of nanofluids flow and heat transfer over a backward-facing step channel. Powder Technology. 2020; 372:497505.

18. Mohammed H A, Alawi O A, Wahid M A. (2015), Mixed convective nanofluid flow in a channel having backward-facing step with a baffle, Powder Technology, 275, 329-343.

19. Ma Y, Mohebbi R, Rashidi MM, Yang Z, Fang Y. Baffle and geometry effects on nanofluid forced convection over forward and backwardfacing steps channel by means of lattice Boltzmann method. Physica A. 2020; 554,124696.

20. Selimefendigil F, Öztop HF. Identification of forced convection in pulsating flow at a backward facing step with a stationary cylinder subjected to nanofluid. Int Communications in Heat and Mass Transfer. 2013;45:111-121.

21. Selimefendigil F, Öztop HF. Numerical investigation and reduced order model of mixed convection at a backward facing step with a rotating cylinder subjected to nanofluid. Computers \& Fluids. 2015b; 109:27-37.

22. Mohammed HA, Fathinia F, Vuthaluru HB, Liu S. CFD based investigations on the effects of blockage shapes on transient mixed convective nanofluid flow over a backward facing step. Powder Technology. 2019;346:441-451.

23. Selimefendigil F, Öztop HF. Effect of a rotating cylinder in forced convection of ferrofluid over a backward facing step. Int J of Heat and Mass Transfer. 2014;71:142-148.

24. Selimefendigil F, Öztop HF. Influence of inclination angle of magnetic field on mixed convection of nanofluid flow over a backward facing step and entropy generation. Advanced Powder Technology. 2015a; 26:1663-1675
25. Hussein AK, Bakier MA, Ben Hamida MB, Sivasankaran S. Magnetohydrodynamic natural convection in an inclined T-shaped enclosure for different nanofluids and subjected to a uniform heat source. Alexandria Engineering J. 2016; 55:2157-2169.

26. Hussain S, Armaghani T, Jamal M. Magnetoconvection and Entropy Analysis in T-Shaped Porous Enclosure Using Finite Element Method. $\mathrm{J}$ of thermophysics and heat transfer. 2019. Available from: https://doi.org/10.2514/1.T5821

27. Geridönmez BP, Öztop HF. Effects of inlet velocity profiles of hybrid nanofluid flow on mixed convection through a backward facing step channel under partial magnetic field. Chemical Physics. 2021; 540:111010

28. Hussain S, Öztop HF. Impact of inclined magnetic field and power law fluid on double diffusive mixed convection in lid-driven curvilinear cavity. Int Communications in Heat and Mass Transfer. 2021; 127:105549. https://doi.org/10.1016/j.icheatmasstransfer.2021.105549

29. Hussain S, Ahmed S E. Unsteady MHD forced convection over a backward facing step including a rotating cylinder utilizing $\mathrm{Fe}_{3} \mathrm{O}_{4}$ water ferrofluid. $\mathrm{J}$ of Magnetism and Magnetic Materials. 2019; 484:356-366.

Meriem Toumi: (D) https://orcid.org/0000-0001-7840-0424

Mohamed Bouzit: (D) https://orcid.org/0000-0002-1417-7291

Fayçal Bouzit: (D) https://orcid.org/0000-0003-4718-0830

Abderrahim Mokhefi: (D) https://orcid.org/0000-0002-2036-2186 